over 6 years responded to one or two nebulised doses. There was a disappointing lack of predictive factors to differentiate between those who responded and those who did not. Even the other significant factors of pulse rate, respiratory rate, and use of rotahaler or aerosol were probably related to age.

When all admissions were considered peak expiratory flow rate was a useful measure of the degree of airway obstruction but was a predictive factor only when a substantial increase occurred after the first nebulised dose. This study has shown, however, that a child aged 6 and over can be safely treated at home with nebulised salbutamol and then reassessed after four hours. No child aged 6 and over who responded initially required intravenous treatment within this period.

Children aged 3 or less are not suitable for home treatment. They need more intensive treatment and are more likely to have faster pulse and respiratory rates, and after the first nebulised dose they may have supraclavicular indraw, a physical sign previously found to be one of the most useful. ${ }^{6}$ Children aged 3 or less made up a surprisingly high proportion of admissions $(32 \%)$. They were difficult to assess clinically : accurate measurement of pulsus paradoxus was impossible, and peak expiratory flow rate could not be measured. Twenty six $(81 \%)$ needed more than two nebulised doses, and intravenous treatment was given to $18\left(56^{\circ}\right)$. Other studies have found young children to be the most severely ill on admission to hospital ${ }^{78}$ and to constitute a high proportion of deaths from asthma. ${ }^{9}$

Most children were able to manage their asthma at home after discharge. The more intensively managed children did not fare any better than the others. Those who were readmitted responded to nebulised salbutamol without intravenous treatment. There are obvious advantages of treatment at home or early discharge from hospital: parents are likely to request earlier treatment if admission to hospital is not automatic; early treatment may be more effective; the child is less likely to be overtreated; and hospital beds may be freed.

This study suggests that children aged 6 and over with asthmatic attacks can be safely treated at home initially, with nebulised salbutamol. We advise that non-responders are admitted to hospital within one hour and responders reassessed at home four hours after treatment. Older children admitted to hospital who improve after one or two nebulised doses can be discharged. Ready access to hospital is an essential back up for either method of treatment, and it must be clearly understood who is responsible for the further care of the patient.

\section{References}

1 Anderson HR. Increase in hospitalisation for childhood asthma. Arch Dis Child 1978;53:295-300

2 Anderson HR, Bailey P, West $S$. Trends in the hospital care of acute childhood asthma 1970-8: a regional study. Br Med F 1980;281:1191-4.

3 Anonymous. Great expectations [Editorial]. Arch Dis Child 1983;58:81. 4 Silverman M. Bronchodilators for wheezing infants ? Arch Dis Child 1984;59:84-7. arber AR, Redmond JV. Acute severe bronchospasm in children: treatment in

general practice. Practitioner $1981 ; 225: 240-2$.
Commey JO, Levison H. Physical signs in childhood asthma. Pediatrics 1976;58: $537-41$.

7 McKenzie SA, Edmunds AT, Godfrey S. Status asthmaticus in children. Arch Dis Child 1979;54:581-6.

8 Simons FER, Pierson WE, Bierment CW. Respiratory failure in childhood status asthmaticus. Am F Dis Child 1977;131:1097-101.

Buranakul B, Washington J, Hilman B, Mancuso J, Sly RM. Causes of death during acute asthma in children. Am $\mathcal{f}$ Dis Child 1974;128:343-50.

\title{
Morbidity and survival in neonates ventilated for the respiratory distress syndrome
}

\begin{abstract}
In a retrospective analysis the records of all (210) infants ventilated to treat the respiratory distress syndrome over three years were reviewed. A mortality of $19 \%$ was found. Intraventricular haemorrhage was associated than a significant increase in mortality in infants of less with 30 weeks' gestation $(p<0.001)$ and was the commonest cause of death. Pneumothoraces developed in one third of babies regardless of gestational age but were significantly associated with an increase in mortality only in infants of 27-29 weeks' gestation. Patent ductus arteriosus was present in 31 infants and was commoner in babies of very low birth weight. The presence of a patent ductus arteriosus was not associated with decreased survival but was significantly related to an increased need for prolonged respiratory support (p<0.001). Thirty six infants developed chronic lung disease, three of whom died.
\end{abstract}

Comparison with data from earlier studies indicated

Department of Paediatrics, University of Cambridge, Cambridge ANNE GREENOUGH, MA, MRCP, clinical lecturer

N R C ROBERTON, MA, FRCP, consultant paediatrician

Correspondence to: Dr A Greenough, Department of Paediatrics, Addenbrooke's Hospital, Cambridge CB2 2QQ. a steady improvement over the past decade in outcome for infants ventilated for the respiratory distress syndrome.

\section{Introduction}

Artificial ventilation is an essential part of treatment for the respiratory distress syndrome when other forms of respiratory support have failed to achieve satisfactory oxygenation or when apnoea develops. Although ventilation of preterm babies is now common practice and mortality and morbidity remain high, few reports on such ventilation have been published recently. Birenbaum et al suggested that mortality might be as high as $38 \%$, with a significant correlation between survival and birth weight, ${ }^{1}$ but this was a considerable improvement on the figures of the last major review in 1977, which quoted an overall mortality of $60 \%$ in babies ventilated for the respiratory distress syndrome. ${ }^{2}$ The increase in survival has been to a certain degree at the expense of increased morbidity, with the emergence of relatively new complications, in particular bronchopulmonary dysplasia and patent ductus arteriosus. Long term problems may also arise in preterm babies who were ventilated. Field et al showed that the duration of ventilation was one of the most important predictors of delay in development in the first year, ${ }^{3}$ and long term respiratory problems, ${ }^{4}$ such as chest infections requiring admission to hospital, are common, particularly if bronchopulmonary dysplasia develops. 
As no recent large study has been done of the immediate mortality and morbidity in preterm babies ventilated to treat the respiratory distress syndrome we analysed our own data to determine the success of this aspect of modern neonatal care, particularly among very low birthweight infants.

\section{Patients and methods}

We reviewed the hospital records of all babies born in or admitted during the first postnatal week to our neonatal intensive care unit over three years (August 1980 to July 1983). Six infants were excluded because of lethal congenital abnormalities (one with triploidy, three with lung hypoplasia, one with Werdnig-Hoffmann disease, and one with muscle fibre disproportion). Two hundred and forty six other infants were ventilated during the period.

In 210 babies the respiratory distress syndrome was diagnosed on the basis of standard criteria (Roberton, 1980). The results in these infants were then analysed for the incidence of major complications such as patent ductus arteriosus, intraventricular haemorrhage, pneumothorax, ventilation requirements for more than one week, and requirement for added oxygen for more than 10 days. The presence of these complications was analysed with respect to both gestational age and birth weight. For this analysis the infants were divided into groups according to gestational age (less than 27, 27-29, and more than 29 weeks) and birth weight (less than 1000, 1000-1500, 15002000 , and more than $2000 \mathrm{~g}$ ). These groupings were chosen as infants of more than 29 weeks' gestation in our neonatal intensive care unit have a relatively low incidence of the respiratory distress syndrome, especially that requiring treatment with ventilation, and infants more immature than 27 weeks' gestation have only recently shown an appreciable survival rate.

Intraventricular haemorrhages were diagnosed by weekly ultrasound examinations or at postmortem examination. Patent ductus arteriosus was diagnosed clinically if, during a routine daily examination, a pansystolic murmur loudest in the pulmonary area was heard together with bounding pulses in association with plethoric lung fields on the chest radiograph. ${ }^{5}$ (Echocardiography was not available in the neonatal intensive care unit.) Chronic lung disease was defined as the need for added oxygen (with or without ventilation) for more than three weeks in the presence of an abnormal chest radiograph showing the characteristic changes of bronchopulmonary dysplasia.

Ninety three infants were ventilated from birth; infants of low (less than 30 weeks') gestation were intubated electively in the resuscitation room ${ }^{6}$ or on transfer to the neonatal intensive care unit unless they established vigorous respiration. As only three infants treated stopped ventilation within six hours the remainder are unlikely to have had important underlying pulmonary pathology. The condition of six infants deteriorated suddenly with the development of a pneumothorax. The indications for ventilation in the others were either recurrent apnoeic attacks or deteriorating blood gases (hypoxaemia and hypercarbia with respiratory acidosis) despite high inspired oxygen concentrations $\left(\mathrm{FrO}_{2} 60-80 \%\right)$ and treatment with continuous positive airways pressure. The decision to start ventilation was influenced by the rate of deterioration and the gestational age of the infant, a more "aggressive" policy being adopted in infants of shorter gestation.

The infants were ventilated by Bournes ventilators (BP 200) via 3.0 or $3.5 \mathrm{~mm}$ nasotracheal tubes. During the acute phase of the respiratory illness all infants received intravenous fluids at a rate of only $60 \mathrm{ml} / \mathrm{kg} / 24 \mathrm{~h}$, which was slowly increased as clinically indicated.

During the three years covered by this retrospective study only two major changes occurred in clinical management. (1) During the initial two years infants were paralysed during ventilation on clinical criteria alone, in particular, poor oxygenation in an agitated baby breathing asynchronously with the ventilator, or because of air leak. In the third year 18 infants were electively paralysed, as they were shown to be actively expiring against the ventilator, in an attempt to reduce air leaks. ${ }^{7}$ (2) Throughout the three years a proportion of the infants were included in a study investigating the effects of artificial surfactant. In the initial period only infants born in the unit and resuscitated at birth were given artificial surfactant, ${ }^{8}$ whereas in the second half of the three years attempts were made to include all infants of less than 34 weeks' gestation in a randomised study. ${ }^{\circ}$ Such infants were randomly allocated to receive either surfactant or a control substance, saline. As a result of the two trials 50 of the infants reported on here received artificial surfactant.

Statisical methods-We used $\chi^{2}$ testing with Yates's correction as necessary.

\section{Results}

Mortality-In the very preterm babies (gestational age less than 27 weeks) the mortality among infants ventilated for the respiratory distress syndrome was $58 \%$ (table I). These deaths comprised almost all those in babies of less than 27 weeks' gestation as only one infant that immature was admitted to the neonatal intensive care unit who did not have the respiratory distress syndrome requiring ventilation. Twenty per cent of infants of 27 and 29 weeks' gestation ventilated for the respiratory distress syndrome died compared with only two infants of over 30 weeks' gestation (both at a gestational age of 31 weeks).

Intraventricular haemorrhages-Twenty $(61 \%)$ of the infants of less than 27 weeks' gestation developed intraventricular haemorrhage (table II). The presence of an intraventricular haemorrhage was associated with a significant increase in mortality in babies of less than 30 weeks' gestation and with a birth weight of less than $1500 \mathrm{~g}$ $(\mathrm{p}<0.001)$ (table II). Babies with intraventricular haemorrhage were more likely to require ventilation for more than one week $(p<0.001)$ and added oxygen for more than 10 days $(p<0.05)$ than were babies without intraventricular haemorrhage. Thirty two of the 60 infants developing intraventricular haemorrhage died. Of the 27 surviving babies, four developed hydrocephalus requiring shunting. One of these four died subsequently and two were known to be developmentally delayed. Six other infants with intraventricular haemorrhage developed cerebral palsy (although one of these infants had also suffered from kernicterus). No neurological problems were diagnosed subsequently in the remaining babies, but four were lost to follow up.

Pneumothoraces-Roughly one third of babies with the respiratory distress syndrome at all gestations and birth weights developed pneumothoraces (table III). The development of a pneumothorax however, caused a significant increase in mortality only in infants of 27-29 weeks' gestations or birth weight $1000-1500 \mathrm{~g}(\mathrm{p}<0 \cdot 01)$. The development of a pneumothorax was not associated with an increased need for added oxygen for more than 10 days but was associated

TABLE I-Details of neonates

\begin{tabular}{ccccc}
\hline $\begin{array}{c}\text { Gestational } \\
\text { age } \\
\text { (weeks) }\end{array}$ & $\begin{array}{c}\text { No } \\
\text { admitted }\end{array}$ & $\begin{array}{c}\text { No developing } \\
\text { the respiratory } \\
\text { distress syndrome }\end{array}$ & $\begin{array}{c}\text { No with the } \\
\text { syndrome } \\
\text { ventilated }\end{array}$ & $\begin{array}{c}\text { No with the } \\
\text { syndrome } \\
\text { dying }\end{array}$ \\
\hline$<26$ & 14 & 14 & 14 & 6 \\
26 & 20 & 19 & 19 & 13 \\
27 & 27 & 26 & 36 & 8 \\
28 & 42 & 37 & 35 & 4 \\
29 & 47 & 46 & 26 & 0 \\
30 & 45 & 32 & 20 & 0 \\
31 & 90 & 42 & 13 & 0 \\
32 & 93 & 33 & 210 & 40 \\
\hline 32 & 658 & 93 & & \\
\hline Total & 1036 & 342 & & \\
\hline
\end{tabular}

TABLE II-Number of infants ventilated for the respiratory distress syndrome according to whether they sustained intraventricular haemorrhage, with numbers dying given in parentheses

\begin{tabular}{|c|c|c|c|c|c|c|c|}
\hline & \multicolumn{3}{|c|}{$\begin{array}{c}\text { Gestational age } \\
\text { (weeks) }\end{array}$} & \multicolumn{4}{|c|}{$\underset{(\mathrm{g})}{\text { Birth weight }}$} \\
\hline & $<27$ & $27-29$ & $>29$ & $<1000$ & $1000-1500$ & $1501-2000$ & $>2000$ \\
\hline \multirow{2}{*}{$\begin{array}{l}\text { Intraventricular } \\
\text { haemorrhage } \\
\text { No intraventricular } \\
\text { haemorrhage }\end{array}$} & 20 (17) & $35(15)$ & $5(0)$ & 25 (19) & $31(13)$ & $3(0)$ & $1(0)$ \\
\hline & $13(2)$ & $59(4)$ & $78(2)$ & $34(3)$ & $70(4)$ & $41(1)$ & $5(0)$ \\
\hline Total & 33 (19) & $94(19)$ & $83(2)$ & $59(22)$ & $101(17)$ & $44(1)$ & $6(0)$ \\
\hline
\end{tabular}

TABLE III-Number of infants ventilated for the respiratory distress syndrome to develop pneumothorax. Numbers dying given in parentheses

\begin{tabular}{lllllllllll}
\hline & \multicolumn{3}{c}{$\begin{array}{c}\text { Gestational age } \\
\text { (weeks) }\end{array}$} & & \multicolumn{5}{c}{$\begin{array}{c}\text { Birth weight } \\
(\mathrm{g})\end{array}$} \\
\cline { 2 - 5 } \cline { 5 - 8 } & $<27$ & $27-29$ & $>29$ & $<1000$ & $1000-1500$ & $1500-2000$ & $>2000$ \\
\hline Pneumothorax & $11(7)$ & $38(15)$ & $23(2)$ & $21(11)$ & $36(12)$ & $12(1)$ & $3(0)$ \\
No pneumothorax & $22(12)$ & $56(4)$ & $60(0)$ & $38(11)$ & $65(5)$ & $312(0)$ & $3(0)$ \\
\hline Total & $33(19)$ & $94(19)$ & $83(2)$ & $59(22)$ & $101(17)$ & $44(1)$ & $6(0)$ \\
\hline
\end{tabular}


with an increased need for assisted ventilation for more than one week $(\mathrm{p}<0.001)$.

Pneumothorax and intraventricular haemorrhage-The development of pneumothoraces and the development of intraventricular haemorrhage were significantly associated with one another $(p<0.001)$, and both were significantly associated with an increase in mortality ( $<<0.001$ ) (table IV). Only four infants who had neither a pneumothorax nor an intraventricular haemorrhage died, of whom two were extremely preterm (less than 24 weeks), one had cytomegalovirus pneumonia, and one had renal failure. Three infants died after developing pneumothoraces without an intraventricular haemorrhage, one owing to an air embolus and the two others from severe respiratory distress syndrome.

Patent ductus arteriosus-Thirty one of the 210 babies developed a patent ductus arteriosus (table V). This was commoner in babies of very low birth weight (less than $1500 \mathrm{~g}$ ) and those of low gestational age (less than 30 weeks). The presence of a patent ductus arteriosus did not have a significant effect on mortality: seven infants with a patent ductus arteriosus died compared with 34 infants without a patent ductus arteriosus. On the other hand, 23 of the 31 infants

\begin{tabular}{|c|c|c|}
\hline $\begin{array}{l}\text { TABLE IV-Asso } \\
\text { ventricular haemo } \\
\text { thorax, and morto } \\
\text { for the respirat } \\
\text { Number of inf } \\
\text { parentheses }\end{array}$ & $\begin{array}{l}\text { tion be } \\
\text { hage (IV } \\
y \text { in info } \\
y \text { distre } \\
\text { is dyin }\end{array}$ & $\begin{array}{l}\text { ween int } \\
\text { H), pneun } \\
\text { ts ventila } \\
\text { syndror } \\
\text { shown }\end{array}$ \\
\hline & No of $i$ & fants with: \\
\hline & IVH & No IVH \\
\hline $\begin{array}{l}\text { Pneumothorax } \\
\text { No pneumothorax }\end{array}$ & $\begin{array}{l}37(21) \\
23(12)\end{array}$ & $\begin{array}{r}35(3) \\
115(4)\end{array}$ \\
\hline
\end{tabular}

survival in this report $(79 \%)$, however, compares favourably with those in previous published reports $\left(41 \%{ }^{10}\right.$ and $40 \%{ }^{2}$ ) and with our own experience in 1975-7 (61\% survival, Roberton, unpublished findings). The data are particularly striking if infants weighing more than $1000 \mathrm{~g}$ are considered alone, particularly those weighing 1000-1500 g. For all infants weighing more than $1000 \mathrm{~g}$ we found an incidence of survival of $88 \%$ compared with an earlier figure of $40 \% .^{2}$ Of those weighing $1000-1500 \mathrm{~g}$ at birth, $84(83 \%)$ survived compared with only 106 out of $446(24 \%)$ in $1977^{2}$ and 12 out of $25(48 \%)$ in Cambridge six years ago (Roberton et al; unpublished findings). For infants weighing less than $100 \mathrm{~g}$ survival on ventilation was a rarity a decade ago and few comparable figures exist (Birenbaum et al found 34\% survival in 19831); the survival rate of $63 \%$ of such infants in this study is therefore particularly encouraging. The improvement in survival compared with the previous studies was unlikely to have been due to differences in the characteristics of the ventilated babies between study groups as our indications for intervention with ventilator treatment were very similar to those quoted in other reports. ${ }^{5} 611$ The aggressive attitude adopted to the resuscitation of infants of short gestation has been reported to improve mortality ${ }^{6}$ and was justified by only small numbers of infants being ventilated for less than six hours, indicating the continuing need of the others for ventilation.

The overall incidence of intraventricular haemorrhage of $29 \%$ compares favourably with the $50-95 \%$ of infants with the respiratory distress syndrome reported by Hellman and Vannucci ${ }^{12}$ but is similar to the $35 \%$ reported by Shinnar et al. ${ }^{13}$ Direct comparison of data may, however, be misleading because of variation in the size and extent of the intraventricular

TABLE $\mathrm{V}-N$ umber of infants ventilated for the respiratory distress syndrome to develop a patent ductus arteriosus

\begin{tabular}{|c|c|c|c|c|c|c|c|}
\hline & \multicolumn{3}{|c|}{ Gestational age (weeks) } & \multicolumn{4}{|c|}{ Birth weight (g) } \\
\hline & $\begin{array}{c}<27 \\
(n=33)\end{array}$ & $\begin{array}{c}27-29 \\
(n=94)\end{array}$ & $\begin{array}{c}>29 \\
(n=83)\end{array}$ & $\begin{array}{r}<1000 \\
(\mathrm{n}=59)\end{array}$ & $\begin{array}{c}1000-1500 \\
(\mathrm{n}=101)\end{array}$ & $\begin{array}{c}1500-2000 \\
(n=44)\end{array}$ & $\begin{array}{l}>2000 \\
(n=6)\end{array}$ \\
\hline $\begin{array}{l}\text { Total with patent ductus arteriosus } \\
\text { Patent ductus arteriosus and death }\end{array}$ & $\begin{array}{l}8 \\
3\end{array}$ & $\begin{array}{r}17 \\
3\end{array}$ & $\begin{array}{l}6 \\
1\end{array}$ & $\begin{array}{r}13 \\
6\end{array}$ & $\begin{array}{r}16 \\
1\end{array}$ & 2 & $\begin{array}{l}0 \\
0\end{array}$ \\
\hline
\end{tabular}

who had a patent ductus arteriosus, compared with 57 of the 179 who did not, required more than 10 days in oxygen $(p<0.001)$ and ventilation for more than one week (16 out of 31 compared with 25 out of $179 ; p<0.001)$. Two infants underwent surgical ligation of their patent ductus arteriosus having failed to respond to indomethacin and fluid restriction. One of these infants subsequently developed subglottic stenosis and remained ventilated until his death from bronchopulmonary dysplasia and a tracheal granuloma; the other died some weeks after surgery with a chronic Staphylococcus epidermidis septicaemia and a large bilateral intraventricular haemorrhage.

Chronic lung disease-Chronic lung disease developed in 36 infants and was commoner in the low gestational age groups ( 10 of 27 infants below 27 weeks' gestation, 22 of 94 of 27-29 weeks' gestation, and four of 83 of more than 29 weeks' gestation). Although infants with a patent ductus arteriosus had a higher incidence of chronic lung disease, this did not reach significance, and there was no such association with the presence of an intraventricular haemorrhage or the development of a pneumothorax. Three infants in this group died, one from cytomegalovirus pneumonia, one from $S$ epidermidis septicaemia and a large intraventricular haemorrhage, and the third also from a large intraventricular haemorrhage; this third infant also had meconium ileus due to cystic fibrosis, diagnosed at postmortem examination.

\section{Discussion}

This study shows that appreciable mortality and morbidity still exist among very low birthweight infants who require ventilation to treat the respiratory distress syndrome. The overall haemorrhages reported. Intraventricular haemorrhage was the commonest cause of death in this study; 31 of the 41 babies who died had an intraventricular haemorrhage, which is similar to the findings of Lindroth et al (54 of 75 in their series). ${ }^{10}$ Mortality $(55 \%)$ in infants with intraventricular haemorrhage was similar to that quoted by Thorburn et al. ${ }^{14}$ In the present study we also found a high morbidity in infants who survived intraventricular haemorrhage, as seen by Shinnar $e t a^{13}$; in the study of Shinnar et al infants with intraventricular haemorrhage remained in hospital for a significantly longer time and had more long term neurological problems, but there was a low incidence of hydrocephalus requiring shunting $(1.8 \%)$ compared with four of $27(15 \%)$ in this series.

Pneumothoraces were a common complication. In the present study the overall incidence was $33 \%$, which is in keeping with previous reports of an incidence ranging from 15 to $40 \% .^{15}$ Pneumothoraces were significantly associated with intraventricular haemorrhage $(p<0.001)$, and as both these factors have previously been shown to be important causes of morbidity and mortality it remains important to try to prevent air leaks during mechanical ventilation. Attempts to do this using paralysing agents have, however, given conflicting results, ${ }^{716}$ but selective paralysis of only those infants at high risk has been associated with a highly significant reduction in the incidence of air leaks. ${ }^{7}$ By adopting this policy in the third year of the present study we may have reduced the number of pneumothoraces by as many as 18 , reducing our incidence by roughly $20 \%$. Results from the initial trial disappointingly failed to show any significant reduction in mortality or numbers of 
intraventricular haemorrhages. ${ }^{7}$ Administration of artificial surfactant could also have improved the mortality and morbidity, but only a minority of the ventilated infants were included in the two trials. Surfactant given at birth was associated with a reduction in mortality ${ }^{8}$ but no difference in the incidence of pneumothoraces; the results from the trial were, however, difficult to interpret owing to the lack of randomised controls. Results from the interim analysis of the second surfactant trial, carried out at the end of the present study, showed no significant differences between the infants treated with surfactant and the controls. If, however, the results from infants of 27-29 weeks' gestation alone were included there were trends in improvement in both mortality and morbidity. ${ }^{9}$

The present study confirms many previous reports of a high incidence of patent ductus arteriosus in babies of very low birth weight ventilated for the respiratory distress syndrome. ${ }^{51718}$

\begin{tabular}{|c|c|c|}
\hline & \multicolumn{2}{|c|}{ Birth weight $(g)$} \\
\hline & $1000-1500$ & $1500-2000$ \\
\hline \multicolumn{3}{|c|}{ Oxford $1972-4$} \\
\hline $\begin{array}{l}\text { Total with syndrome } \\
\text { Deaths ( }{ }^{\circ} \text { survival) }\end{array}$ & $\begin{array}{l}41 \\
13(68)\end{array}$ & $\begin{array}{l}35 \\
6(82)\end{array}$ \\
\hline \multicolumn{3}{|c|}{ Cambridge 1975-7 } \\
\hline $\begin{array}{l}\text { Total with syndrome } \\
\text { Deaths ( }{ }^{\circ} \text { survival) }\end{array}$ & $\begin{array}{l}37 \\
13(65)\end{array}$ & $\begin{array}{l}58 \\
3\end{array}$ \\
\hline \multicolumn{3}{|c|}{ Cambridge 1980-3 } \\
\hline $\begin{array}{l}\text { Total with syndrome } \\
\text { Deaths (" }{ }_{0} \text { survival) }\end{array}$ & $\begin{array}{l}101 \\
17(83)\end{array}$ & $\stackrel{44}{1}(98)$ \\
\hline
\end{tabular}

The overall incidence of patent ductus arteriosus in this series $(15 \%)$ is, however, considerably lower than that reported in previous studies $\left(21^{\circ} \%\right.$ Siassi et al, ${ }^{17} 21-62 \%$ Rudd et $\left.a l^{19}\right)$. The incidence in the infants with a birth weight of less than $1000 \mathrm{~g}$ is also lower $(22 \%)$ than the $47 \%$ reported by Brown. ${ }^{20}$ As in the series reported by Siassi et al, ${ }^{17}$ no infant suffering from the respiratory distress syndrome, with a birth weight greater than $2000 \mathrm{~g}$, developed a patent ductus arteriosus. The low incidence in the present study may well have been due to our fluid restriction policies in the first postnatal days, as the incidence is very similar to that reported by Pickering et al from Oxford, where similar fluid restriction policies are practised. ${ }^{21}$ We found that in the presence of a patent ductus arteriosus significantly more babies required ventilation for longer than one week and required added oxygen for more than 10 days.

In babies with a patent ductus arteriosus the incidence of bronchopulmonary dysplasia was increased. This is in line with previous reports: Cotton et al found that it was common for infants who had a patent ductus arteriosus to require prolonged ventilation ${ }^{22}$; Merritt et al found an increased dependence on added oxygen treatment and in the incidence of bronchopulmonary dysplasia among infants with a patent ductus arteriosus ${ }^{23}$; and this was confirmed by Brown, who showed a highly significant association between bronchopulmonary dysplasia and the presence of a patent ductus arteriosus $(p<0.001) .{ }^{20}$ The survival of infants with a patent ductus arteriosus, and with a birth weight of less than $1500 \mathrm{~g}$, was $76 \%$ in the present series, which is identical to the $75 \%$ survival in similar infants without a patent ductus arteriosus. This compares favourably with a previous study, ${ }^{22}$ in which Cotton et al reported that only $44^{\circ} \%$ of infants with a patent ductus arteriosus and birth weight less than $1500 \mathrm{~g}$ survived longer than 72 hours.

Chronic lung disease developed in $17 \%$ of the present series, being commoner with decreasing gestational age. (This is similar to the $13 \%$ quoted by Lindroth. ${ }^{10}$ ) Although in that series and that of Bryan et al (eight of 11$)^{24}$ there was a much lower overall survival rate than in the present study, this may be explained by the differences in definitions used.

The overall mortality from the respiratory distress syndrome of infants, including those who were not ventilated, in this report is $11.7 \%$, which appears to be similar to that reported from Oxford 10 years ago. ${ }^{25}$ If, however, only infants weighing greater than $1000 \mathrm{~g}$ at birth are considered the overall mortality for the respiratory distress syndrome falls to only $4.6 \%$ compared with $9.5 \% .{ }^{25}$ If birthweight specific figures are considered (table VI) it can be seen that during the past decade there has been a steady improvement in the outcome for infants of very low birth weight suffering from the respiratory distress syndrome as the techniques used in neonatal intensive care have become more successful.

We thank Professor J A Davis, Dr C J Morley, and Dr G Gandy for their help and encouragement and particularly Dr G Gandy, who provided the data on the incidence of the respiratory distress syndrome. Dr G Gandy and Dr A Dixon performed all the ultrasound examinations. Lastly, we thank all the nursing and medical staff of the special care baby unit of the then Mill Road Maternity Hospital, without whose excellent care these results would not have been possible.

\section{References}

1 Birenbaum E, Brish M, Lison M. Evaluation of respiratory support therapy in 135 newborn babies: survival and respiratory complications. Isr $\mathcal{F}$ Med $S_{c}$ 135 newborn

2 Roberton NRC. Management of neonatal respiratory failure $f R$ Coll Physicians Lond 1977;11:389-400.

3 Field MT, Dempsey JR, Ting GT, et al. Respiratory distress syndrome: perinatal prediction of one year developmental outcome. Semin Perinatol 1982;6 288-93.

4 Kamper J. Ventilatory support of preterm infants. Results and long-term prognosis. Dan Med Bull 1979;26:155-6.

Kitterman JA, Edmunds H, Gregory GA, Heymann MA, Tooley WH, Rudolph AM. Patent ductus arteriosus in premature infants. Incidence, relation to pulmonary disease and management. $N$ Engl $\mathcal{A}$ Med 1972;287:473-7.

A death from hyaline membrane disease. Arch Dis Child 1982;57:184-6.

thoraces in ventilated premature infants who actively expire against pneumopressure ventilation. Lancet $1984 ; 1: 1-4$

8 Morley CJ, Miller N, Bangham AD, Davis JA. Dry artificial lung surfactant and its effect on very premature babies. Lancet $1981 ; \mathrm{i}: 64-8$.

9 Bangham AD, Miller NGA, Davies RJ, Greenough A, Morley CJ. Introductory remarks about artificial lung expanding compounds (ALEC). Colloids and Surfaces 1984;10:337-4 10 Lindroth M, Svenningsen NW, Ahlstrom H, Jonson B. Evaluation of mechanical

1 Reynolds EOR. Management of hyaline membrane disease. Br Med Bull 1975 $31: 18-24$.

12 Hellman J, Vannucci $R$. Intraventricular haemorrhage in premature babies. Semin Perinatol 1982;6:42-51.

13 Shinnar S, Molteni RA, Gammon K, D'Souza BJ, Altman J, Freeman JM. Intraventricular haemorrhage in the premature infant. $N$ Engl $\mathcal{F}$ Med 1982; $306: 1464-8$.

14 Thorburn RJ, Lipscomb AP, Stewart AL, Reynolds EOR, Hope PL. Timing and antecedents of periventricular haemorrhage and of cerebral atrophy in very preterm infants. Early Hum Dev 1982;7:221-38.

15 Primak RA. Factors associated with pulmonary air leak in premature infants receiving mechanical ventilation. F Pediatr 1983;102:764-9. mechanical ventilation speeds recovery of the lungs with hyaline membrane disease. Lancet $1981 ; \mathrm{i}: 346-8$.

17 Siassi B, Blanco B, Cabal LA, Coran AG. Incidence and clinical features of patent ductus arteriosus in low birthweight infants: a prospective analysis of 150 consecutive born infants. Pediatrics 1976;57:347-51.

18 Heymann MA. Patent ductus arteriosus. In: Moss AJ, Adams FH, Emmanouilides GC, eds. Heart disease in infants, children and adolescents. Baltimore: Williams and Wilkins, 1977:168.

19 Rudd P, Montanez P, Hallidie-Smith K, Silverman M. Indomethacin treatment for patent ductus arteriosus in very

trial. Arch Dis Child 1983;58:267-70. Pediatr 1979;95:865-6.
Pew Increased risk

21 Pickering D, Rigby ML, Wilkinson AR. Incidence and clinical features of patent ductus arteriosus in premature infants with respiratory distress syndrome. Pediatr Cardiol 1983;4:39-4

22 Coton RB, Stahlman MT, Kovar I, Catterron WZ. Medical management of small preterm babies with symptomatic patent ductus arteriosus. $\mathcal{F}$ Pediat

23 Merrit TA, Harris JP, Roghmannik K. Early closure of the patent ductus arteriosus

24 Bryan MH, Hardie MJ, Reilley BJ, Swyer PR. Pulmonary function studies during the first year of life in infants recovering from the respiratory distress

25 Roberton NRC, Tizard JPM. Prognosis for infants with idiopathic respiratory distress syndrome. Br Med $\mathcal{F}$ 1975;ii:271-4.

(Accepted 4 December 1984) .

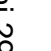

